\title{
3-D model simulations of dynamical and microphysical interactions in pyroconvective clouds under idealized conditions
}

\section{P. Reutter et al.}

Correspondence to: P. Reutter (preutter@uni-mainz.de) 
Supplement to

\section{„3D model simulations of dynamical and microphysical interactions in pyro-convective clouds under idealized conditions"}

In this supplement the vertical velocity and the volume mean radius are presented.

In the following, the $y-z$ cross sections of the vertical velocity for all three cases are shown for 30, 60, 90 and 120 minutes, respectively.

$\mathrm{N}_{\mathrm{CN}}=200 \mathrm{~cm}^{-3}$
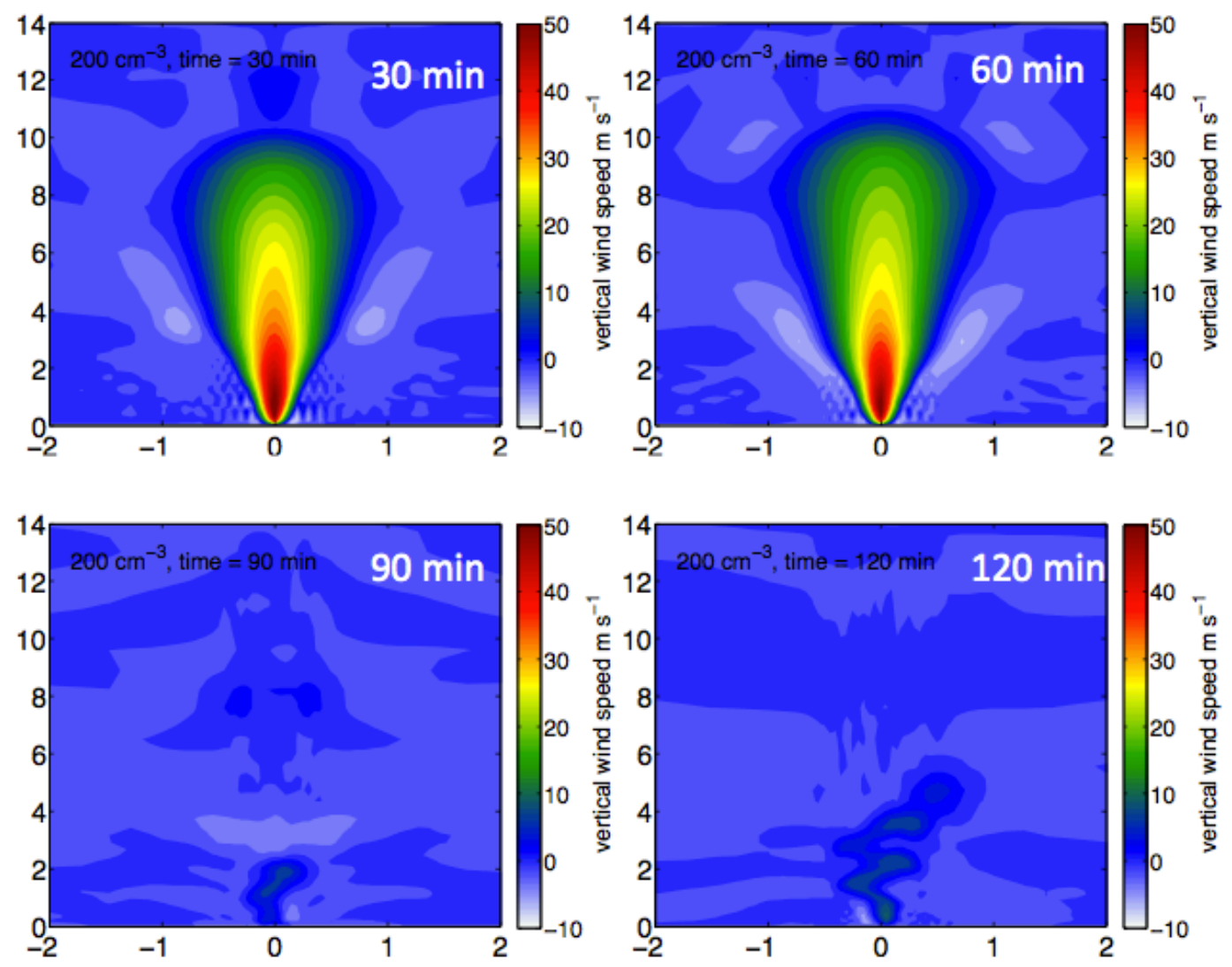

Figure 1: $Y-Z$ cross section of the vertical velocity for the case with $N_{C N}=200 \mathrm{~cm}^{-3}$ after 30, 60, 90 and 120 minutes after simulation start. 
$\mathrm{N}_{\mathrm{CN}}=1000 \mathrm{~cm}^{-3}$
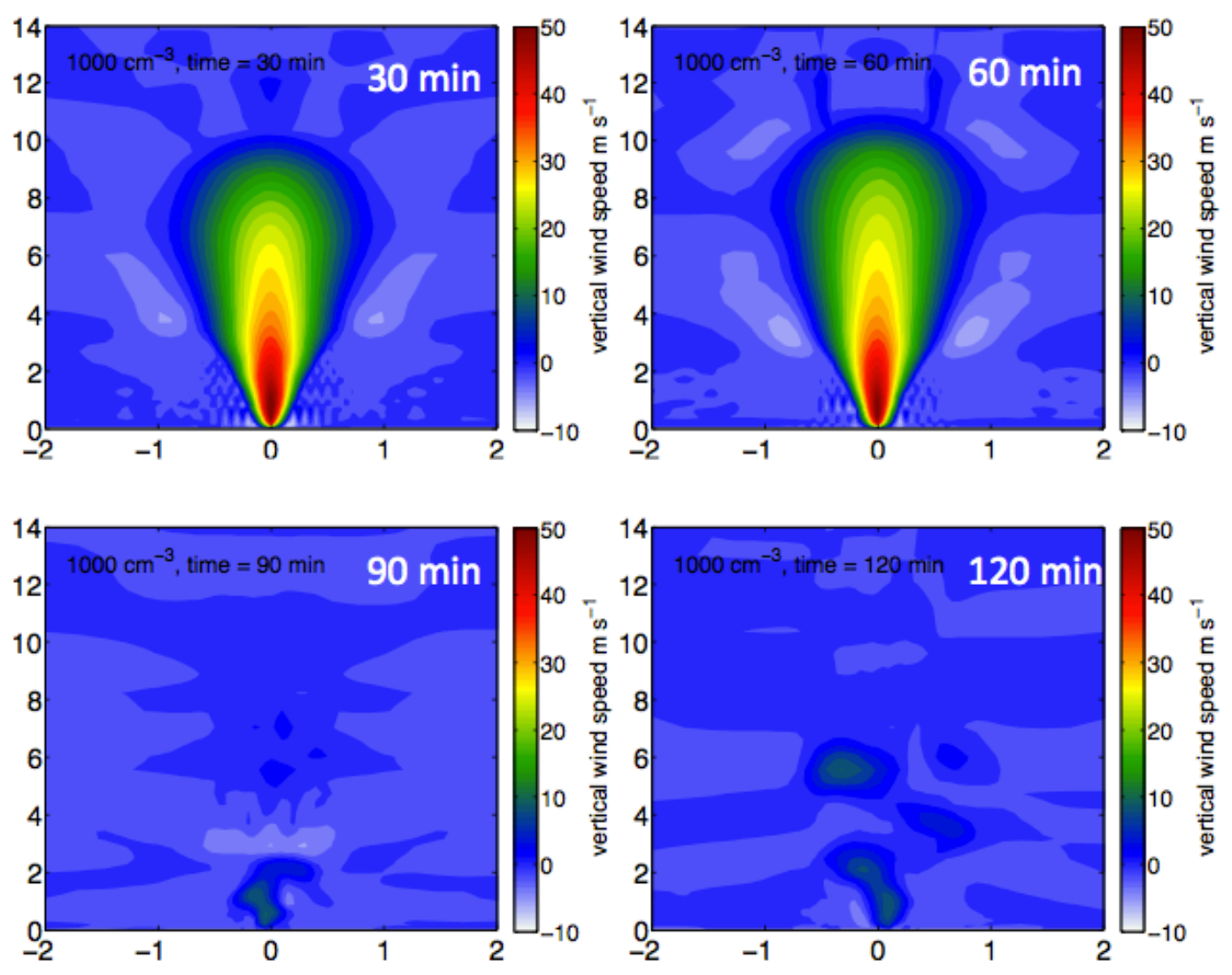

Figure 2: $Y-Z$ cross section of the vertical velocity for the case with $N_{C N}=1000 \mathrm{~cm}^{-3}$ after $30,60,90$ and 120 minutes after simulation start. 
$N_{C N}=20000 \mathrm{~cm}^{-3}$
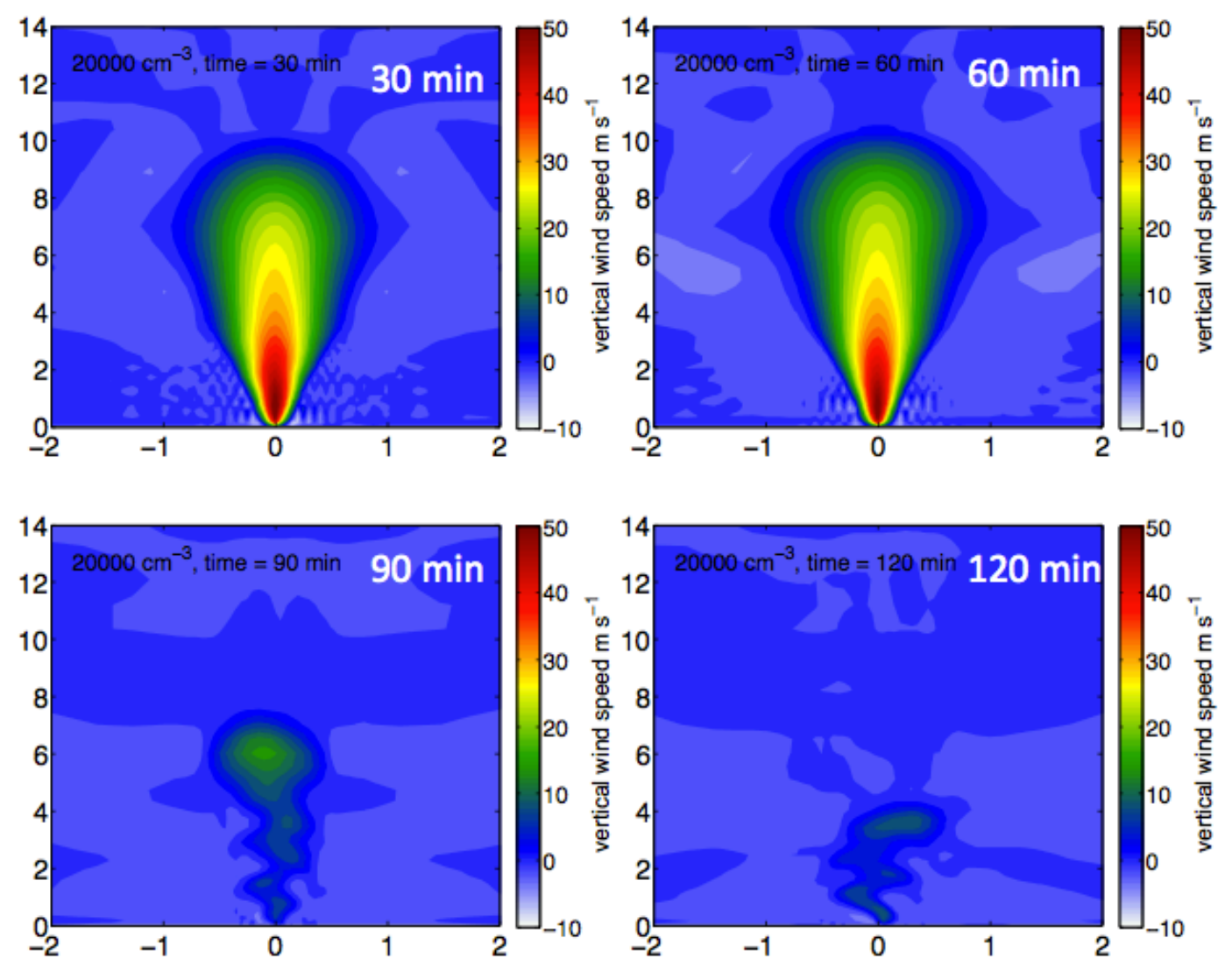

Figure 3: Y-Z cross section of the vertical velocity for the case with $N_{C N}=20000 \mathrm{~cm}^{-3}$ after $30,60,90$ and 120 minutes after simulation start. 
Volume mean radius after 60 minutes after simulation start.
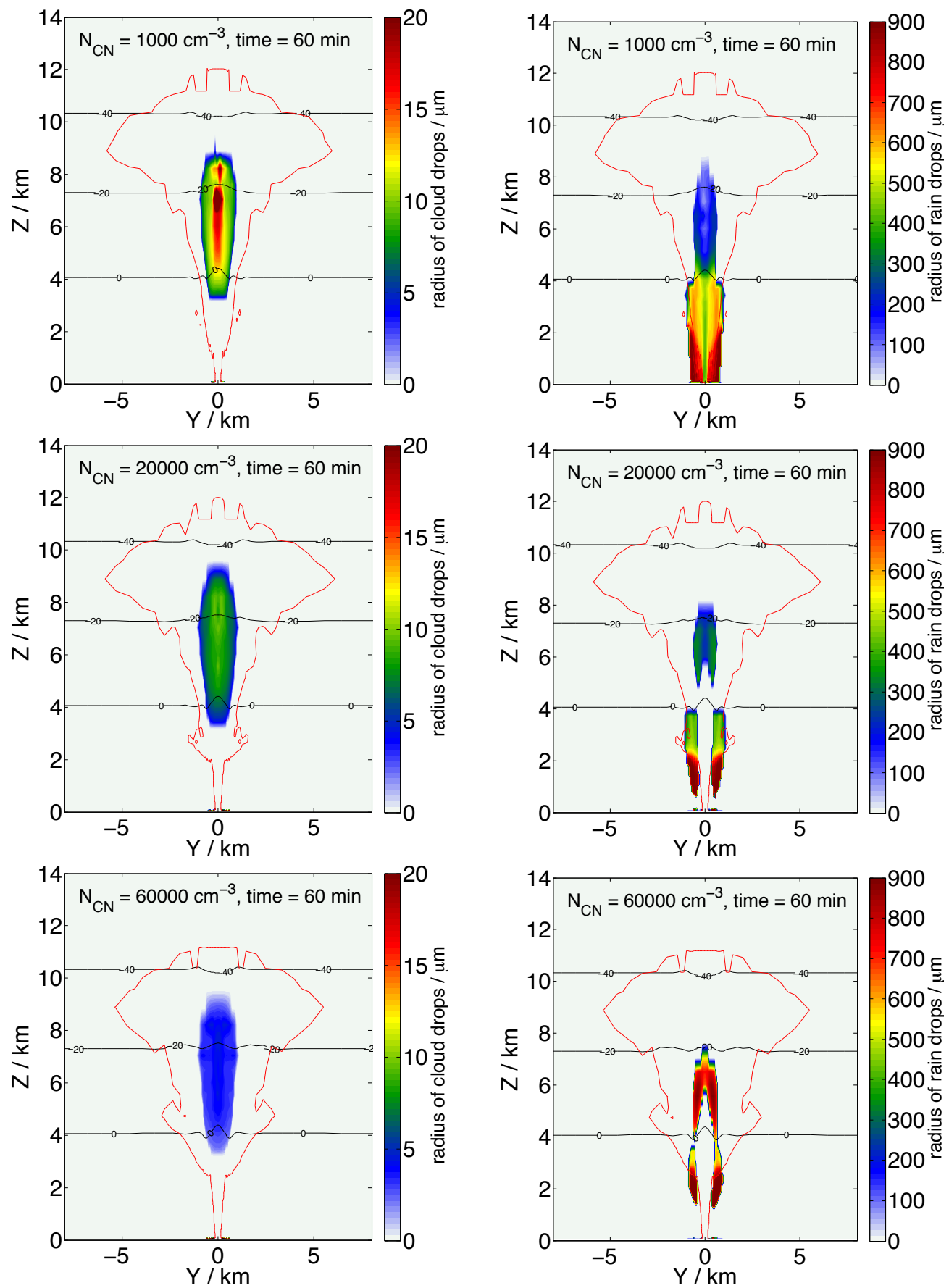

Figure 4: $Y-Z$ cross section at $x=0 \mathrm{~km}$ of the volume mean radius of (left column) cloud water in $\mu \mathrm{m}$ and (right column) rain water in $\mu \mathrm{m}$ for (top row) the clean case, (middle row) the intermediate case and (bottom row) the strongly polluted case. The black lines denote the $0 \circ \mathrm{C}, 0-20^{\circ} \mathrm{C}$ and $-40{ }^{\circ} \mathrm{C}$ isothermes, respectively. The red line shows the $0.1 \mu \mathrm{g} \mathrm{kg}^{-1}$ isoline of the interstitial aerosol. 

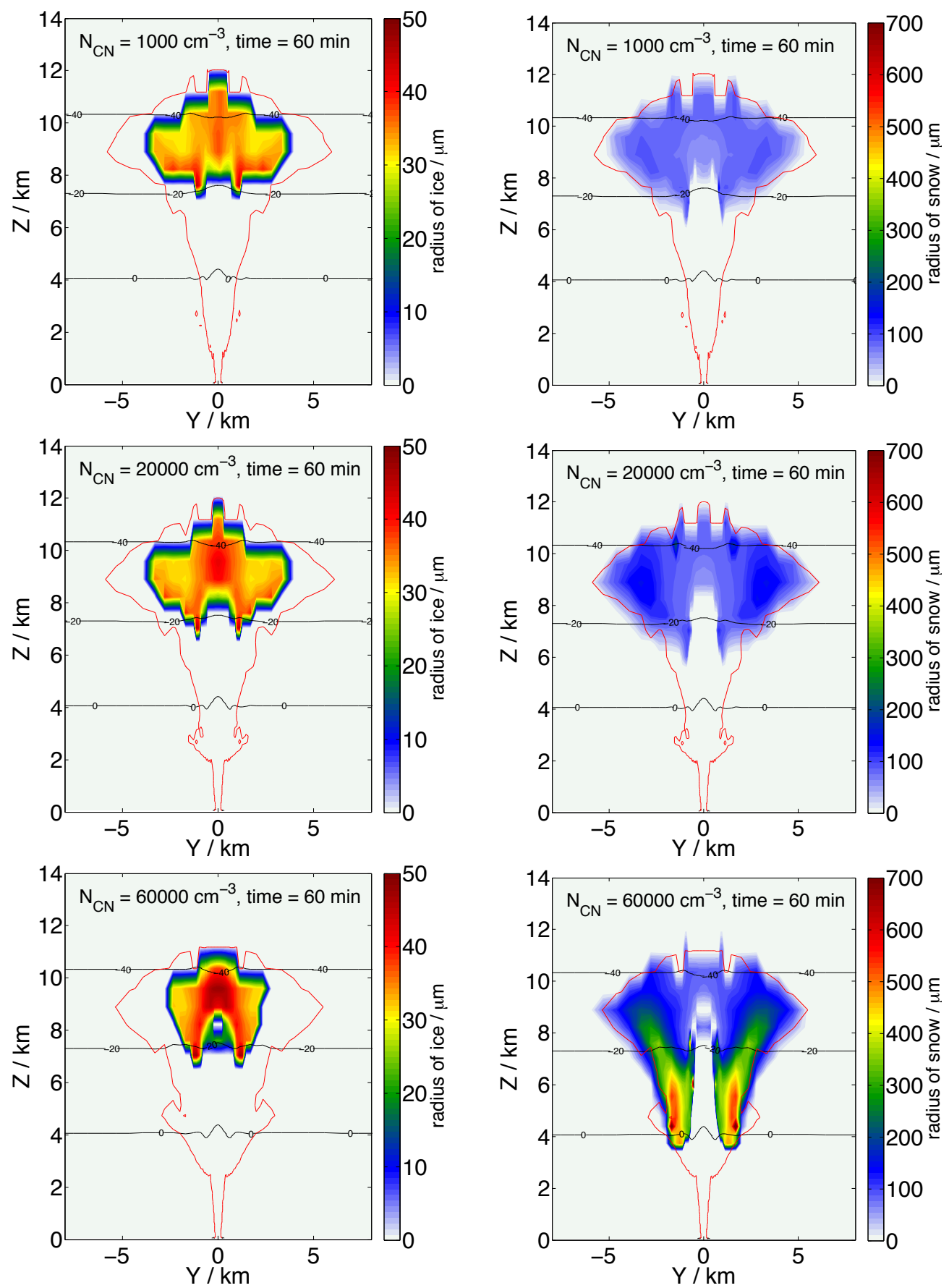

Figure 5: $Y-Z$ cross section at $x=0 \mathrm{~km}$ of the volume mean radius of (left column) ice crystals in $\mu \mathrm{m}$ and (right column) snow particles in $\mu \mathrm{m}$ for (top row) the clean case, (middle row) the intermediate case and (bottom row) the strongly polluted case. The black lines denote the $0{ }^{\circ} \mathrm{C}, 0-20^{\circ} \mathrm{C}$ and $-40{ }^{\circ} \mathrm{C}$ isothermes, respectively. The red line shows the $0.1 \mu \mathrm{g} \mathrm{kg}^{-1}$ isoline of the interstitial aerosol. 

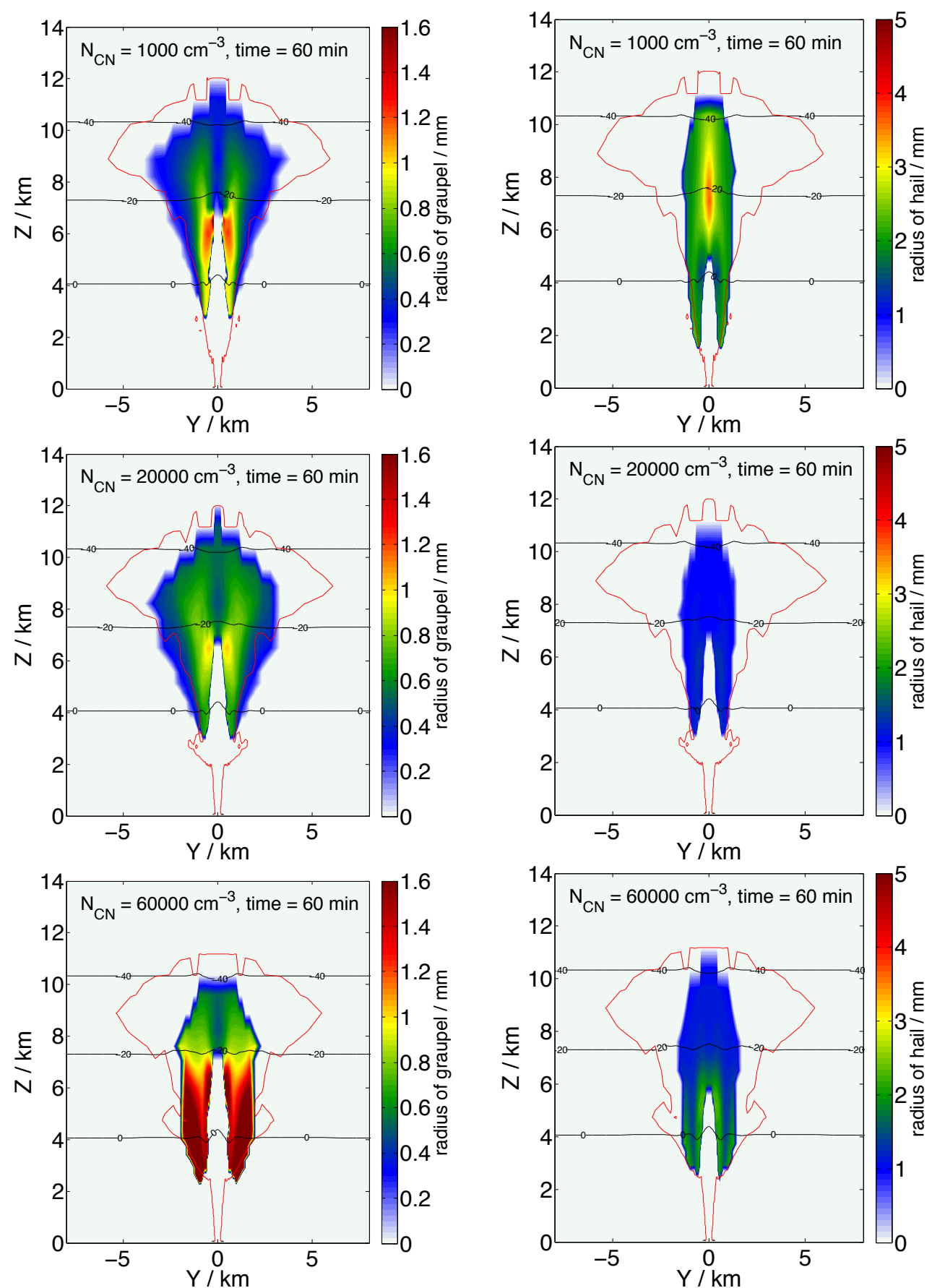

Figure 6: $Y-Z$ cross section at $x=0 \mathrm{~km}$ of the volume mean radius of (left column) graupel in $\mu \mathrm{m}$ and (right column) hail in $\mu \mathrm{m}$ for (top row) the clean case, (middle row) the intermediate case and (bottom row) the strongly polluted case. The black lines denote the $0{ }^{\circ} \mathrm{C}, 0-20^{\circ} \mathrm{C}$ and $-40{ }^{\circ} \mathrm{C}$ isothermes, respectively. The red line shows the $0.1 \mu \mathrm{g} \mathrm{kg}^{-1}$ isoline of the interstitial aerosol. 